\title{
Conservation of weathered historic sandstone with biomimetic apatite
}

\author{
YANG FuWei ${ }^{1 *}$, LIU Yan ${ }^{1}$, ZHU YuanCheng ${ }^{1}$, LONG ShiJia ${ }^{1}$, ZUO GuoFang $^{1}$, \\ WANG ChangQing ${ }^{1}$, GUO Feng ${ }^{1}$, ZHANG BingJian ${ }^{2}$ \& JIANG SiWei ${ }^{3}$ \\ ${ }^{1}$ Key Laboratory for New Molecule Material Design and Function, Tianshui Normal University, Tianshui 741000, China; \\ ${ }^{2}$ Department of Chemistry, Zhejiang University, Hangzhou 310027, China; \\ ${ }^{3}$ The Art Museum of Dazu Rock Carvings, Chongqing 632360, China
}

Received August 17, 2011; accepted November 28, 2011; published online March 31, 2012

\begin{abstract}
The conservation of weathered historic sandstone with apatite was studied. Based on the growth mechanism of bone, calcium and phosphorus were introduced into weathered sandstone and then mineralized at room temperature. The conservation efficiency was investigated by scanning electron microscopy (SEM), energy-dispersive X-ray spectroscopy (EDX), transmission electron microscopy (TEM), selected area electron diffraction (SAED), X-ray diffraction (XRD), and compressive strength, capillary water uptake, water vapor permeability and weather resistance tests. The SEM, EDX, TEM, SAED and XRD results showed that the produced hydroxyapatite could reunite the weathered stone blocks and provide sufficient reinforcement to hold them together. The results of the various tests indicated that the compressive strength and weather resistance of the treated samples was improved significantly. In addition, because of the porous nature of apatite, the water vapor permeability of the treated stone was not affected and its breathability was maintained.
\end{abstract}

historic sandstone, apatite, biomimetic, conservation

Citation: $\quad$ Yang F W, Liu Y, Zhu Y C, et al. Conservation of weathered historic sandstone with biomimetic apatite. Chin Sci Bull, 2012, 57: 2171-2176, doi: $10.1007 /$ s11434-012-5039-9

Carbonate cement is extensively distributed in the sandstone cultural relics of China [1-3]. Its content in these historic sandstones is usually as high as $10 \%$, and sometimes is even up to $20 \%$ [4]. Carbonate is susceptible to weathering and can be corroded by carbon dioxide in the presence of water [5]. Acidic air pollutants such as sulfur dioxide [6] and nitric oxide [7] increase the rate of corrosion of stone relics [8]. The loss of carbonate cement leads to the decay of valuable sandstones; they become porous, loose and even disaggregated [9]. Serious damage has been observed at the Yungang [10], Longmen [11], Baodingshan [12] and Longyou Grottoes [13].

In the past, polymeric resins such as silicones [14], acrylic resins [15], and fluorinated polymers [16] have often been employed as consolidants to conserve sandstone relics. However, these materials either provide insufficient protection, exhibit poor weatherability, or both [17]. Polymeric

*Corresponding author (email: zhuoyingyang@126.com) resins are not stable enough to preserve sandstone relics. They degrade rapidly in the open air because of microorganism attack [18], and thermal- [19] and photo-aging [20]. In addition, polymeric resins are not compatible with the historic stones [21], which are inorganic in nature. In most cases, polymeric materials strongly reduce the water permeability of treated stones. As a consequence, water condensation and the accumulation of harmful agents inside the stone can occur, resulting in the dissolution of minerals, growth of bacteria, exfoliation, cracks, and detachment of the underlying matrix [22]. Therefore, synthetic organic polymers are no longer considered suitable materials to preserve historic stones [23].

Inorganic consolidants including sodium silicate, ethyl silicate and a colloidal suspension of silica have been used to preserve sandstone relics [24]. These consolidants can reduce the porosity of the material, making it more compact and less susceptible to the effects of water. In addition, because of the nature of silicon, these consolidants have better 
compatibility with sandstone than polymeric resins. However, soluble salts from silicate could cause weathering of sandstone relics [25].

In this paper, weathered historic sandstone is conserved with apatite. Similar to the growth mechanism of animal bones, calcium (dispersion of lime hydrate in alcohol) and phosphorus (ammonium phosphate) were introduced into the weathered stone and then mineralized at room temperature. After mineralization, a kind of porous, interlinked apatite phase is produced that can reunite broken sandstone blocks to conserve valuable relics.

\section{Experimental}

\subsection{Materials}

A. R. grade calcium oxide $(\mathrm{CaO})$, Vaseline, 1-propanol and ammonium phosphate $\left(\left(\mathrm{NH}_{4}\right)_{3} \mathrm{PO}_{4}\right)$ were used without further purification. The simulated test blocks of weathered moderate-grain sandstone (cylinders that were $3.0 \mathrm{~cm}$ high and $5.0 \mathrm{~cm}$ in diameter) were made according to a method described in the literature [26]. An evenly blended mixture of $\mathrm{CaCO}_{3}$ powder $(5 \mathrm{~g})$, mid sand $(45 \mathrm{~g})$ and deionized water $(6.0 \mathrm{~mL})$ were added into a cylinder shaped mold, and then a hammer was dropped 12 times from a height of 277 $\mathrm{mm}$ to compress the sample. The obtained test blocks were stored at $25^{\circ} \mathrm{C}$ and $60 \pm 5 \%$ humidity for $7 \mathrm{~d}$ prior to use.

\subsection{Preparation and characterization of the dispersion of lime hydrate}

Lime hydrate was prepared as follows: calcium oxide powder was added to distilled water (the mass ratio of calcium oxide to water was $1: 5$ ) with agitation and the slaking temperature was held at $80 \pm 10^{\circ} \mathrm{C}$. The obtained lime putty was stored for 6 months in an airtight container before use.

A dispersion of lime hydrate in 1-propanol was prepared in a rotary evaporator. First, the lime hydrate was enriched at a temperature of $80^{\circ} \mathrm{C}$. When a ratio of $\mathrm{Ca}(\mathrm{OH})_{2} / \mathrm{H}_{2} \mathrm{O}=$ 0.6 was reached, 1-propanol was added to give a suspension with a final concentration of $10 \mathrm{~g} / \mathrm{L}$.

\subsection{Conservation of simulated stone test blocks}

The dispersion of lime hydrate in 1-propanol (10 g/L, 25 $\mathrm{mL}$ ) was introduced into the test blocks by spraying. After the introduction of calcium, ammonia phosphate solution $(10.0 \%, 25 \mathrm{~mL})$ was sprayed into the test blocks. The test blocks treated with lime hydrate and ammonia phosphate were stored at $25^{\circ} \mathrm{C}$ and $80 \pm 5 \%$ humidity for 2 weeks prior to testing.

\subsection{Physicochemical characterization}

The morphologies of the samples were observed by scan- ning electron microscopy (SEM, FEI SIRION-100, USA) and transmission electron microscopy (TEM, FEI TECNAIG-F20, USA). The crystal structures of the samples were investigated by X-ray diffraction (XRD, AXS D8 ADVANCE, German) using $\mathrm{Cu} \mathrm{K} \alpha$ radiation ( $\lambda=1.54 \AA$ ), at $40 \mathrm{kV}$ and $40 \mathrm{~mA}$. The absorbance of the dispersion of lime hydrate, $A$, was measured at $600 \mathrm{~nm}$ using an ultraviolet/visible spectrophotometer (Varian Cary 100, USA) immediately after the dispersion of lime hydrate was prepared. The relative kinetic stability of the dispersion was defined as $\xi$, which was calculated using eq. (1) [27]:

$$
\xi=\left\{1-\left[\left(A_{t=0}-A_{t}\right) / A_{t=0}\right]\right\} \times 100 \% \text {. }
$$

\subsection{Assessment of the conservation efficiency}

The conservation efficiency of the consolidant was estimated by compressive strength, capillary water uptake, water vapor permeability and weather resistance tests. The compressive strength was determined with a hydraulic universal testing machine (YC-125B, Shanghai, China). During the test, the pressure loading rate was $0.01 \mathrm{MPa} / \mathrm{s}$. The capillary water uptake was determined according to the method described in the National Standard JGJ/T70-2009 [28]. The water vapor permeability was determined using the wet cup method: first, the test block was placed on a glass cup containing distilled water and sealed with Vaseline. The air gap between the base of the test block and the water was $10 \mathrm{~mm}$. The glass cup with the sealed test block was then placed in a humidistat at a relative humidity of $50 \%$ and weighed every $24 \mathrm{~h}$ until steady state vapor transmission was achieved. Weather resistance experiments were carried out using the method described in the National Standard JGJ/T70-2009, Part 11 [28]: a test block was immersed in saturated $\mathrm{NaCl}$ solution at $20^{\circ} \mathrm{C}$ for $4 \mathrm{~h}$, and then frozen at $-15^{\circ} \mathrm{C}$ for another $4 \mathrm{~h}$. These steps were repeated until the test blocks were obviously destroyed.

\section{Results and discussion}

\subsection{Preparation of the dispersion of lime hydrate}

SEM images of the prepared lime hydrate are presented in Figure 1. The size of the lime hydrate particles is in the range of $\sim 150-700 \mathrm{~nm}$. This kind of submicron lime hydrate particle can also be synthesized by hydrolysis of $\mathrm{CaCl}_{2}$ with aqueous $\mathrm{NaOH}$ [29]. However, this hydrolysis reaction is hard to control and removing the $\mathrm{NaCl}$ produced is very troublesome [30]. The XRD results (Figure 2a) indicate that the prepared lime hydrate is predominantly crystalline $\mathrm{Ca}(\mathrm{OH})_{2}$ (portlandite) [31]. Calcium carbonate, which is often presented as a consequence of carbonation in the hydrolysis method [32], was not observed.

The kinetic stability of dispersions of lime hydrate in 1-propanol and water is presented in Figure 3. The dispersion of lime hydrate in water is not stable (Figure 3a). In 


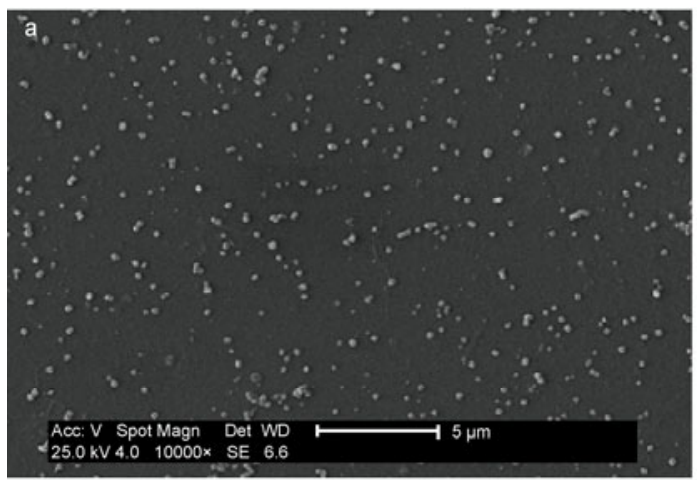

Figure 1 SEM images of the prepared lime hydrate particles.

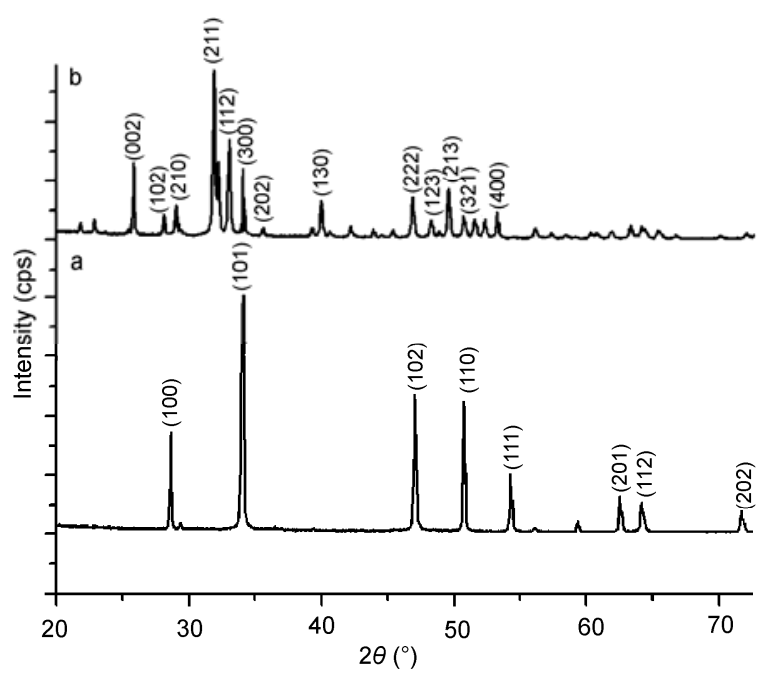

Figure 2 XRD patterns of: a, the prepared lime hydrate; b, the interlocked structure.

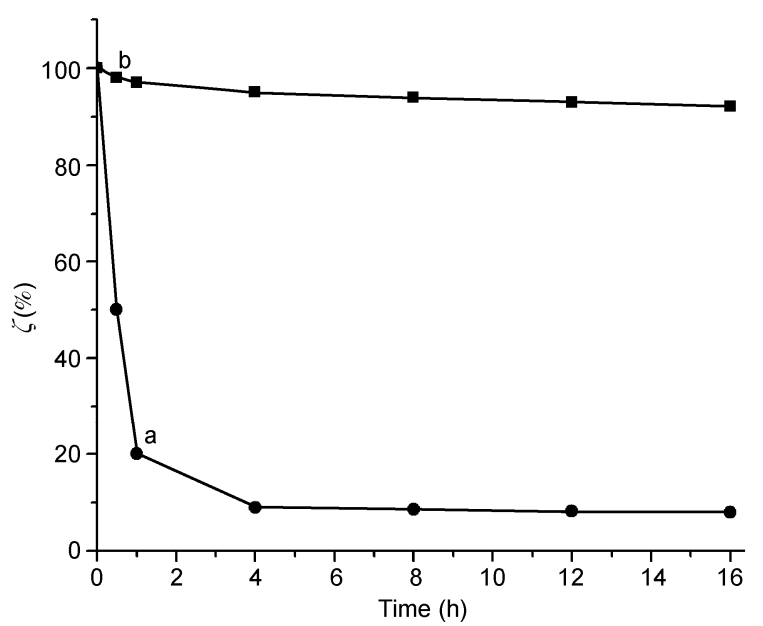

Figure 3 Kinetic stability of dispersions of lime hydrate in: a, water; b, 1-propanol.

contrast, the dispersion of lime hydrate in 1-propanol is stable for more than $16 \mathrm{~h}$ (Figure $3 \mathrm{~b}$ ). This is attributed to the small dimensions of the particles and hydrophobic interactions that prevent sedimentation and aggregation of the lime hydrate particles [33].

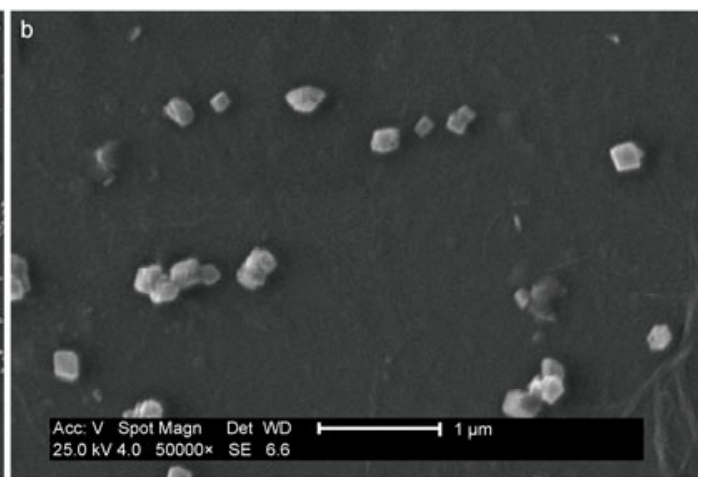

\subsection{Conservation of sandstone test blocks}

Figure 4a shows the cross-sectional morphology of the weathered sandstone, which exhibits a broken, rough appearance. Figure $4 \mathrm{~b}$ shows the cross-sectional morphology of the weathered sandstone treated by the dispersion of lime hydrate. After treatment, the holes and cracks in the weathered stone were filled with lime hydrate particles. Lime water [34] and calcium bicarbonate solution [35] have previously been used as consolidants for weathered historic stones. The consolidation mechanism lies in the carbonation reaction (2) of calcium hydroxide or the decomposition reaction of calcium dicarbonate (3):

$$
\begin{gathered}
\mathrm{Ca}(\mathrm{OH})_{2}+\mathrm{CO}_{2}=\mathrm{CaCO}_{3}+\mathrm{H}_{2} \mathrm{O} \\
\mathrm{Ca}\left(\mathrm{HCO}_{3}\right)_{2}=\mathrm{CaCO}_{3}+\mathrm{CO}_{2}+\mathrm{H}_{2} \mathrm{O}
\end{gathered}
$$

However, because of the low solubility of calcium hydroxide and calcium bicarbonate, the amount of calcium introduced is limited and the calcium carbonate produced by these methods often exists as isolated particles [34,35] rather than as a continuous carbonate phase. Obviously, isolated particles can only act as fillers and are unlikely to provide sufficient consolidation. Because of its higher calcium content and stability, the dispersion of lime hydrate in alcohol is a better calcium carrier and pore filler than an aqueous calcium solution. However, it is not an efficient consolidant either because the particles do not form a continuous phase.

After the introduction of the dispersion of lime hydrate, the weathered sandstone test blocks were treated with ammonia phosphate. Two weeks later, the test blocks were cut into slices and investigated. The cross-sectional morphology of these treated test blocks is presented in Figure 4c,d. After treatment with both calcium and phosphate, a porous and interlocked structure is produced (Figure 4c). Because of this interlocked structure, the broken sandstone blocks are reunited (Figure 4d). The composition of the interlocked structure was characterized by EDX. EDX results show that it is composed of $\mathrm{Ca}, \mathrm{P}$, and $\mathrm{O}$, and the molar ratio of $\mathrm{Ca} / \mathrm{P}$ is 1.67 (Table 1), which is equal to the $\mathrm{Ca} / \mathrm{P}$ ratio of hydroxyapatite. A high resolution TEM image and SAED 

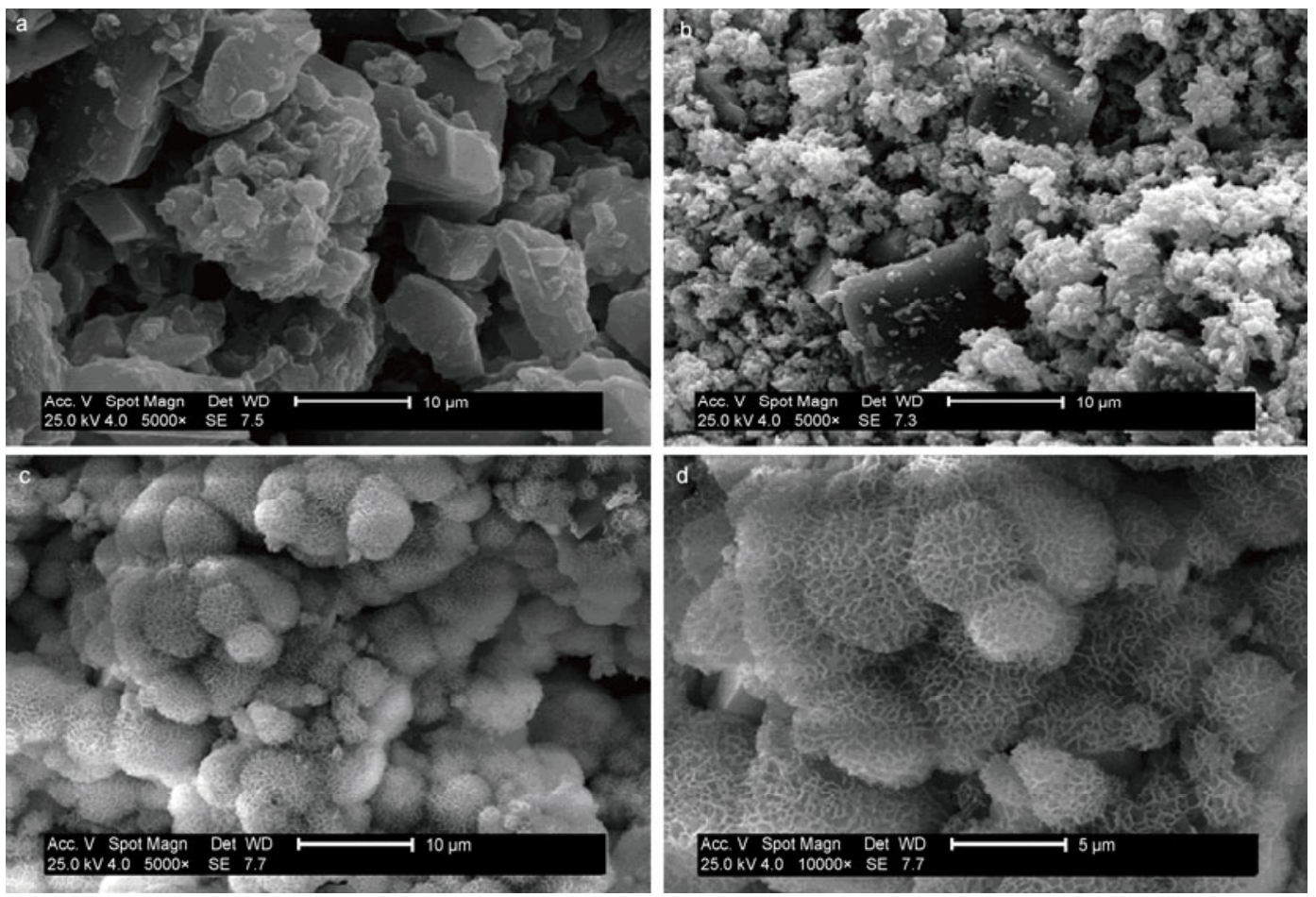

Figure 4 Cross-sectional SEM images of test blocks. a, Untreated; b, treated with a dispersion of lime hydrate; c and d, treated with the biomimetic method.

Table 1 EDX analysis of the interlocked structure

\begin{tabular}{ccc}
\hline Element & Wt (\%) & At (\%) \\
\hline $\mathrm{O}$ & 37.33 & 57.72 \\
$\mathrm{P}$ & 19.77 & 15.78 \\
$\mathrm{Ca}$ & 42.90 & 26.50 \\
\hline
\end{tabular}

pattern of the interlocked structure were also obtained (Figure 5). The treated sample possesses a sheet-like morphology. There are distinct diffraction rings in the SAED pattern, indicating that the sheet-like structure is completely polycrystalline. Its crystal parameters (4.702, 3.448, 2.297, 1.875 and $1.486 \AA$ ) are consistent with those of hydroxyapatite $(4.709,3.441,2.296,1.871$ and $1.474 \AA$ ) [36]. The characteristic diffraction peaks of hydroxyapatite can be easily distinguished in the XRD patterns (Figure 2b) of the interlocked structure. From these results, the composition of the interlocked structure is hydroxyapatite [37], the most stable phosphate in nature [38]. Analytical results obtained using the Jade program [39] indicate that the crystallinity of the hydroxyapatite crystals is $90.727 \%$, which is consistent with the SAED results. Hydroxyapatite forms through the metasomatic reaction of lime hydrate and phosphate. According to previous studies, the metasomatic reaction is a dissolution-recrystallization process [40]. The related reactions are

$$
\begin{gathered}
\mathrm{Ca}(\mathrm{OH})_{2} \rightarrow \mathrm{Ca}^{2+}+2 \mathrm{OH}^{-} \\
5 \mathrm{Ca}^{2+}+3 \mathrm{PO}_{4}{ }^{3-}+\mathrm{OH}^{-} \rightarrow \mathrm{Ca}_{5}\left(\mathrm{PO}_{4}\right) 3 \mathrm{OH}
\end{gathered}
$$

In this study, after treatment with ammonia phosphate

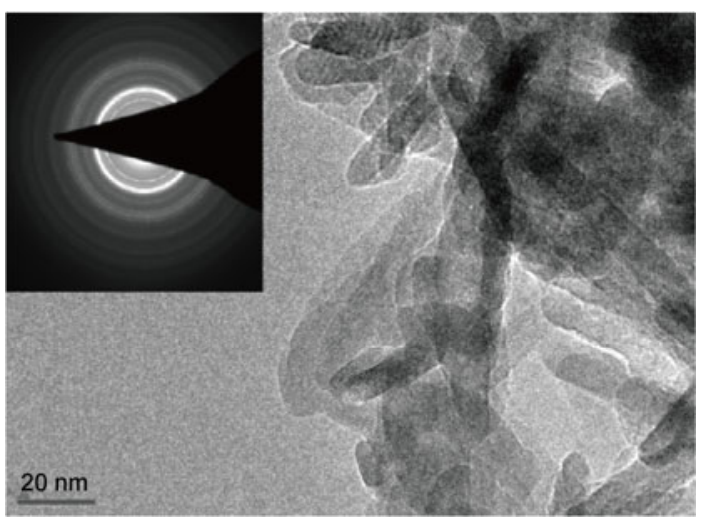

Figure 5 TEM images of the interlocked structure.

solution, $\mathrm{Ca}^{2+}$ ions from dissolved lime hydrate react with $\mathrm{PO}_{4}{ }^{3-}$ ions, and then reprecipitate in the form of hydroxyapatite. Through this metasomatic reaction, lime hydrate changes to hydroxyapatite and exists as a continuous phase (Figure 4d) rather than as separate particles. As a result, the porous and broken sandstone blocks are reunited by the continuous hydroxyapatite phase, which provides efficient reinforcement.

\subsection{Assessment of the conservation efficiency}

The compressive strengths of the untreated and treated samples are listed in Table 2. The compressive strength is less than $0.05 \mathrm{MPa}$ for the untreated sandstone sample. The biomimetic treatment method is very effective because the 
Table 2 Properties of the samples before and after treatment with a dispersion of lime hydrate and the biomimetic method

\begin{tabular}{lcc}
\hline \multicolumn{1}{c}{ Samples } & Water uptake $(\%)$ & Vapor diffusivity $\left(\mathrm{cm} \mathrm{s}^{-1}\right)$ \\
\hline Untreated & $18.61(1.26)$ & $5.52 \times 10^{-6}\left(0.80 \times 10^{-6}\right)$ \\
Treated with biomimetic method & $18.50(0.64)$ & $5.26 \times 10^{-6}\left(0.60 \times 10^{-6}\right)$ \\
\hline
\end{tabular}

treated sample has a compressive strength of more than 2.50 $\mathrm{MPa}$. Undoubtedly, this is caused by the interlocked hydroxyapatite structure, which can bind weathered stone blocks together and provide substantial reinforcement.

The results of capillary water uptake test are also listed in Table 2 . The capillary water uptake of the test blocks is decreased after the biomimetic treatment, implying that the treatment makes the stone samples more compact and less permeable to water. Low capillary action can protect the stone against erosion by water and soluble salts or bases.

The water vapor permeability of test blocks decreases only slightly after the biomimetic treatment (Table 2), suggesting that it is a suitable conservation procedure because the water vapor permeability is not changed significantly and the breathability of the original material is hardly affected [41].

The stone samples treated by the biomimetic method have good frost and salt resistance. Even after at least 10 cycles of the freezing-melting experiment, the samples maintained an intact appearance and good mechanical strength. The losses of weight and compressive strength of the treated samples are both less than $5.0 \%$ after 10 cycles.

\section{Conclusion}

Biomimetic conservation of historic sandstone with apatite was studied. A dispersion of lime hydrate in 1-propanol, and ammonia phosphate were introduced into weathered stone and then mineralized at room temperature. The resulting interlinked apatite integrated the weathered sandstone blocks together, providing reinforcement. The test results indicate that this method significantly improves the compressive strength and weather resistance of treated stone samples. After treatment, the capillary water uptake decreased, the water vapor permeability was largely unaffected and the breathability of the stone samples was retained. These results suggest that this biomimetic method is a good candidate for the conservation of weathered historic sandstone.

This work was supported by the Key Project of the Chinese Ministry of Education (211189) and "QingLan" Talent Engineering Funds of Tianshui Normal University.

1 Zhang Z X, Fu L S, Yao J S, et al. Lithological characters of carved sandstone in Dazu (in Chinese). J Chongqing Jianzhu Univ, 1995, 17: 58-62

2 Li Z X. The rock features of the grottoes along the old Silk Road and its consolidation in conservation (in Chinese). Dunhuang Res, 2002,
4: 73-83

3 Li L, Tanimoto $\mathrm{C}$. The preliminary investigation of the geological environment of the Longyou grottoes and its existing disease (in Chinese). Dunhuang Res, 2002, 4: 92-96

4 Ma Z P, Huang J Z, Zhang H. Chemical weathering of carbonate cement in sandstone and the related cultural relic diseases in Yungang grottoes (in Chinese). Carsol Sin, 2005, 24: 71-82

5 Ge Y, Jie D M, Guo J X, et al. Response of phytoliths in Leymus chinensis to the simulation of elevated global $\mathrm{CO}_{2}$ concentrations in Songnen Grassland, China. Chin Sci Bull, 2010, 55: 3703-3708

6 Zhang Y H, Xie S D. Choice of control of sulfur and/or nitrogen deposition based on critical loads. Chin Sci Bull, 2010, 55: 493-498

7 Camaiti M, Bugani S, Bernardi E, et al. Effects of atmospheric $\mathrm{NO}_{x}$ on biocalcarenite coated with different conservation products. Appl Geochem, 2007, 22: 1248-1252

8 Siegfried S, Rolf S, Joerg R. Monument futures: Climate change, air pollution, decay and conservation-the Wolf-Dieter Grimm-volume. Environ Geol, 2008, 56: 451-453

9 Domenico C, Piergiulio C, Alessio L, et al. The ornamental stones of Caserta province: The Campanian Ignimbrite in the medieval architecture of Casertavecchia. J Cult Herit, 2004, 5: 137-148

10 Yang X J, Peng T, Li G G, et al. Study on long term strength of pillar rockmass at Yungang grottoes (in Chinese). Chin J Rock Mech Eng, 2009, 28: 3402-3408

11 Wang X G, Peng T, Guo Y Q, et al. Deformation causes of Longmen grottoes and control countermeasures (in Chinese). Chin J Geol Hazard Control, 2006, 17: 130-132

12 Jiang S W. Hardness efflorescence in Baodingshan Grott (in Chinese). Sci conserv Archaeol, 1999, 11: 18-21

13 Li L, Wang S J, Tanimoto C, et al. Study of weathering characteristics of sandstone at Longyou Grottoes (in Chinese). Chin J Rock Mech Eng, 2008, 16: 798-805

14 Zendri E, Biscontin G, Nardini I, et al. Characterization and reactivity of silicatic consolidants. Constr Build Mater, 2007, 21: 1098-1106

15 Iñigo A C, Vicente-Tavera S, Rives V, et al. Color changes in the surface of granitic materials by consolidated and/or water repellent treatments. Color Res Appl, 1997, 22: 133-141

16 He L, Nie M Q, Liang G Z. Preparation and feasibility analysis of fluoropolymer to the sandstone protection. Prog Org Coat, 2008, 62: 206-213

17 Liu F C, Hao Y S, Wang Z Y, et al. Flaking and degradation of polyurethane coatings after 2 years of outdoor exposure in Lhasa. Chin Sci Bull, 2010, 55: 650-655

18 Cappitelli F, Sorlini C. Microorganisms attack synthetic polymers in items representing our cultural heritage. Appl Environ Microbiol, 2008, 74: 564-569

19 Lazzari M, Chiantore O. Thermal-ageing of paraloid acrylic protective polymers. Polymer, 2000, 41: 6447-6455

20 Favaro M, Mendichi R, Ossola F, et al. Evaluation of polymers for conservation treatments of outdoor exposed stone monuments. Part I: Photo-oxidative weathering. Polym Degr Stab, 2006, 91: 3083-3096

21 Bugani S, Camaiti M, Morselli L, et al. Investigating morphological changes in treated vs. untreated stone building materials by X-ray micro-CT. Anal Bioanal Chem, 2008, 391: 1343-1350

22 Moropoulou A, Kouloumbi N, Haralampopoulos G, et al. Criteria and methodology for the evaluation of conservation interventions on treated porous stone susceptible to salt decay. Prog Org Coat, 2003, 48: 259-270

23 Grassi S, Favaro M, Tomasin P, et al. Nanocontainer aqueous systems for removing polymeric materials from marble surfaces: A new and promising tool in cultural heritage conservation. J Cult Herit, 
2009, 10: 347-355

24 Fidler J. New research on inorganic solvents offers improved techniques for masonry conservation. Conserv Bull, 2004, 45: 33-35

25 Moreno F, Vilela S A G, Antunes Â S G, et al. Capillary-rising salt pollution and granitic stone erosive decay in the parish church of Torre de Moncorvo (NE Portugal)—implications for conservation strategy. J Cult Herit, 2006, 7: 56-66

26 Yang F W, Liu Y, Zhang B J, et al. Biomimic conservation of weathered calcareous stones by apatite. New J Chem, 2011, 35: 887-892

27 Gabrielli G, Cantale F, Guarini G G T. Adsorption of amphiphilic mixtures and stabilization of suspensions of hydrophobic solids in water. Colloid Surface A, 1996, 119: 163-174

28 Standard for Test Method of Performance on Building Mortar (JGJ/T70-2009)

29 Daniele V, Taglieri G, Quaresima R. The nanolimes in cultural heritage conservation: Characterisation and analysis of the carbonation process. J Cult Herit, 2008, 9: 294-301

30 Ambrosi M, Dei L, Giorni R, et al. Colloidal particles of $\mathrm{Ca}(\mathrm{OH})_{2}$ : Properties and applications to restoration of Frescoes. Langmuir, 2001, 17: 4251-4255

31 Salvadori B, Dei L. Synthesis of $\mathrm{Ca}(\mathrm{OH})_{2}$ nanoparticles from Diols. Langmuir, 2001, 17: 2371-2374

32 Giorgi R, Chelazzi D, Baglioni P. Nanoparticles of calcium hydroxide for wood conservation. The deacidification of the Vasa Warship.
Langmuir, 2005, 21: 10743-10748

33 Giorgi R, Dei L, Ceccato M, et al. Nanotechnologies for conservation of cultural heritage: Paper and canvas deacidification. Langmuir, 2002, 18: 8198-8203

34 Price $\mathrm{C}$ A. The consolidation of limestone using a lime poultice and limewater. Stud Conserv, 1984, 29: 158-159

35 Tiano P, Cantisani E, Sutherland I, et al. Biomediated reinforcement of weathered calcareous stones. J Cult Herit, 2006, 7: 49-55

36 International Centre for Diffraction Data. The Powder Diffraction File (54-0022), 2003

37 Kumar E, Xie J, Chittur K, et al. Transformation of modified brushite to hydroxyapatite in aqueous solution: Effects of potassium substitution. Biomaterials, 1999, 20: 1389-1399

38 Wang L J, Lu J W, Xu F S, et al. Dynamics of crystallization and dissolution of calcium orthophosphates at the near-molecular level. Chin Sci Bull, 2011, 56: 713-721

39 Jiang C H, Wu D, Hu J W, et al. Application of chemical fractionation and X-ray powder diffraction to study phosphorus speciation in sediments from Lake Hongfeng, China. Chin Sci Bull, 2011, 56: 2098-2108

40 Ratner M, Ni B D. Nacre surface transformation to hydroxyapatite in a phosphate buffer solution. Biomaterials, 2003, 24: 4323-4331

41 Mosquera M J, de los Santos D M, Montes A, et al. New nanomaterials for consolidating stone. Langmuir, 2008, 24: 2772-277

Open Access This article is distributed under the terms of the Creative Commons Attribution License which permits any use, distribution, and reproduction in any medium, provided the original author(s) and source are credited. 